\title{
Eutectic MC carbide growth morphologies of a laser clad TiC/FeAl composite coating
}

\author{
Y. Chen ${ }^{\mathrm{a}, \mathrm{b}, *}$, H.M. Wang ${ }^{\mathrm{b}}$ \\ ${ }^{a}$ Laboratory for Laser Intelligent Manufacture, Institute of Mechanics, Chinese Academy of Sciences, 15 Beisihuanxi Road, Beijing 100080, P.R. China \\ ${ }^{\mathrm{b}}$ Laboratory of Laser Materials Processing and Surface Engineering, School of Materials Science and Engineering, Beihang, University, \\ 37 XueYuan Road, Beijing 100083, P.R. China
}

Received 20 April 2005; accepted 15 June 2005

Available online 21 July 2005

\begin{abstract}
In this paper, eutectic MC carbide growth morphology and its evolution with laser scanning speed were studied comprehensively of a laser clad MC carbide reinforced FeAl intermetallic matrix composite coating. As the laser scanning speed increased, the growth morphology of eutectic MC carbide was found to be needle-aligned annulation, butterfly-like and well-developed dendrite.

(C) 2005 Elsevier B.V. All rights reserved.
\end{abstract}

Keywords: Carbide; Crystal growth; Laser processing

\section{Introduction}

FeAl intermetallic alloy is of interest for potential structural material in industrial applications because of its excellent resistance to oxidation and high-temperature sulfidation, low density and high melting melt (1250-1400 $\left.{ }^{\circ} \mathrm{C}\right)[1,2]$. However, the industrial application is mainly limited by the low fracture toughness and mediocre mechanical properties above $600{ }^{\circ} \mathrm{C}$. With the intention to utilize FeAl intermetallic alloy for high-temperature structural applications, composites with $\mathrm{FeAl}$ as the matrix have been the focus of many investigations [3-6], in which TiC type $\mathrm{MC}$ carbide is found to be a suitable reinforcement for improving the mechanical properties of $\mathrm{FeAl}$ alloy due to the combination of excellent high temperature stability, high hardness and low density. However, only few investigations have, so far, been devoted to fabrication $\mathrm{TiC}$ reinforced $\mathrm{FeAl}$ composite as the coating materials. From the tribological

\footnotetext{
* Corresponding author. Laboratory for Laser Intelligent Manufacture, Institute of Mechanics, Chinese Academy of Sciences, 15 Beisihuanxi Road, Beijing 100080, P.R. China. Tel.: +86 10 62651165; fax: +86 10 62521859 .

E-mail address: chenyao27@163.com (Y. Chen).
}

point of view, $\mathrm{TiC}$ reinforced $\mathrm{FeAl}$ matrix composites is expected to possess excellent abrasive resistance due to high hardness of TiC. Additionally, the strong atomic bonds and relatively high hardness of $\mathrm{FeAl}$ alloy make it difficult to be deformed during contacting with metallic mating materials. Our previous research $[7,8]$ reported that $\mathrm{TiC}$ reinforced FeAl intermetallic matrix composite coating has been successfully fabricated using laser cladding technique, and such coating has excellent wear resistance under both roomand high-temperature dry sliding wear conditions.

It is well known that the growth morphology of the reinforcement has strong effect on the mechanical properties of these composites, and therefore it is necessary to study the growth morphology of $\mathrm{TiC}$ type $\mathrm{MC}$ carbide in laser clad $\mathrm{TiC} / \mathrm{FeAl}$ composite coating. Previously, considerable research has been carried out on $\mathrm{TiC}$ type $\mathrm{MC}$ carbide in different solidification conditions and different alloy system. The near-equilibrium growth morphology of MC carbide in nickel-base superalloys are octahedral blocks and these would transform gradually to Chinese-script morphology, flower-like and radially branched colonies with increasing cooling rate [9-12]. Meanwhile, the growth morphologies of MC carbide of a laser surface alloyed $\gamma$-TiAl alloy with carbon is found to have a faceted dendritic morphology 


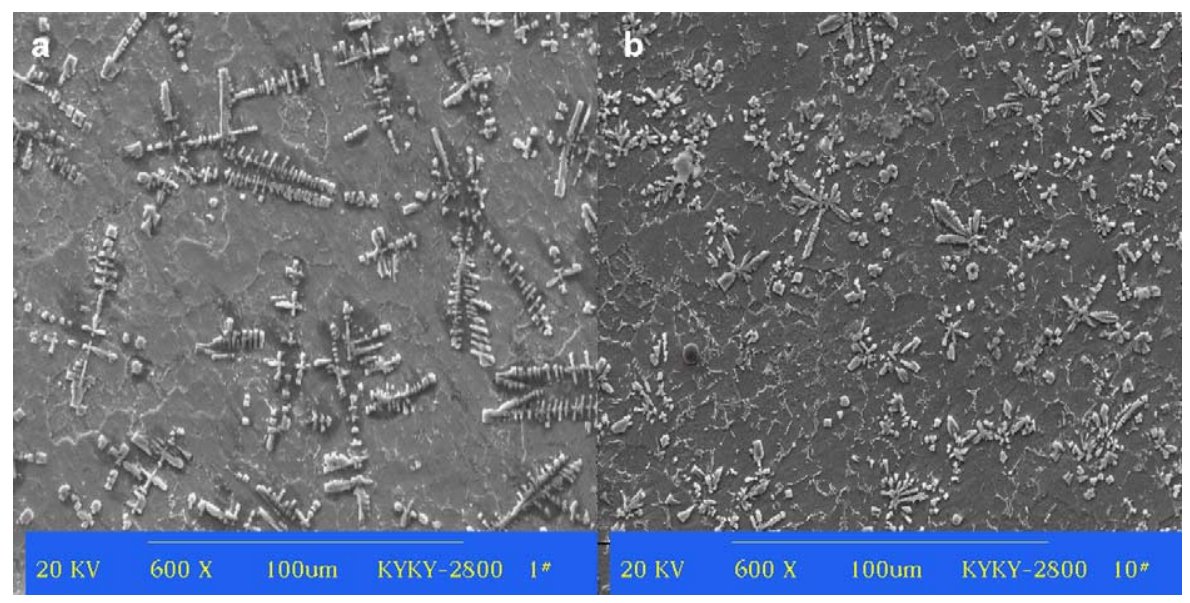

Fig. 1. Typical microstructure of laser clad TiC/FeAl composite coating with a laser scanning speed of $5 \mathrm{~mm} / \mathrm{s}$ (a) and $10 \mathrm{~mm} / \mathrm{s}$ (b).

having zig-zag platelet or three-dimensional faceted-platelet networks on the growth surface of dendritic arms [13], cross-petal-like with symmetrical arms and irregular block or undeveloped dendrite [14]. Also, a unique radialbranching dendritic primary $\mathrm{MC}$ carbide, nucleates heterogeneously on the surface of oxide particles, was found in laser clad $\mathrm{TiC} / \mathrm{FeAl}$ composite coatings in our previous research. In this paper, the rapidly solidified growth morphologies of eutectic TiC type MC carbide in laser clad $\mathrm{TiC} / \mathrm{FeAl}$ composite coatings were investigated.

\section{Experimental procedures}

The stainless steel of $1 \mathrm{Cr} 18 \mathrm{Ni} 9 \mathrm{Ti}, 15 \times 10 \times 8 \mathrm{~mm}$ in size, was selected as substrate for laser cladding treatment, and the

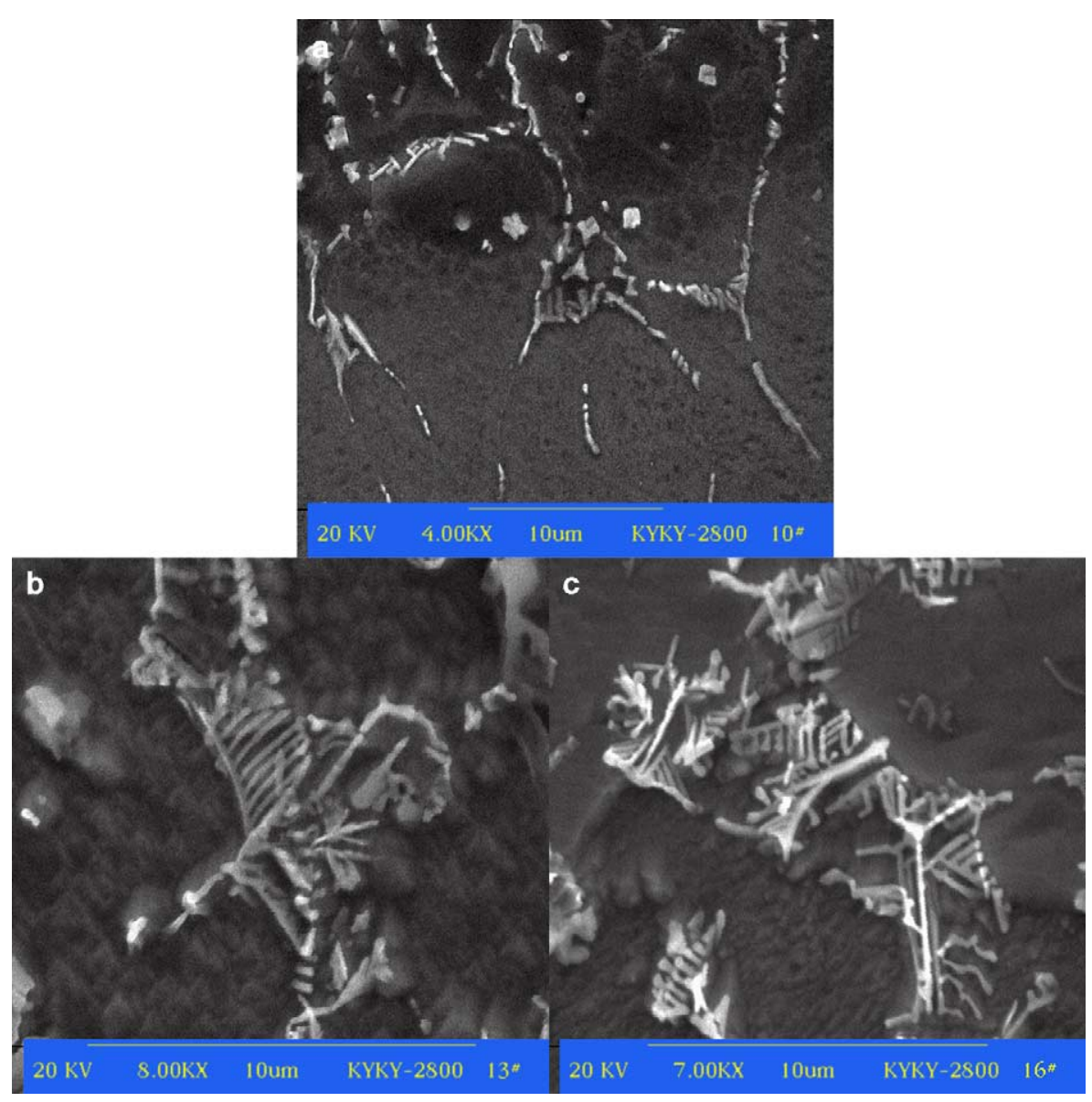

Fig. 2. SEM micrographs showing the typical growth morphologies of eutectic MC carbide in laser clad TiC/FeAl composite coating with a laser scanning speed of $5 \mathrm{~mm} / \mathrm{s}$ (a), $8 \mathrm{~mm} / \mathrm{s}$ (b) and $10 \mathrm{~mm} / \mathrm{s}$ (c). 
surface of samples were cleaned and coated with black paint in order to increase the laser absorption coefficient of the material. The starting precursor materials were prepared from $\mathrm{Fe}-28 \mathrm{Al}-4 \mathrm{Ti}-4 \mathrm{C}$ (at.\%), then pre-placed on the substrate surface, approximately $1.5 \mathrm{~mm}$ in thickness. A $5 \mathrm{~kW} \mathrm{CO}$ continuous wave laser was adopted for laser cladding. The laser processing parameters are: laser power $2.8 \mathrm{~kW}$, beam diameter $3.0 \mathrm{~mm}$, laser scanning speed $5 \sim 10 \mathrm{~mm} / \mathrm{s}$.

The transverse and longitudinal sections of laser clad coating were mechanically polished and etched by $\mathrm{HCl}+\mathrm{H}_{2} \mathrm{O}(1: 1)$ solution at room temperature. Microstructure and the growth morphologies of eutectic $\mathrm{TiC}$ carbide in laser clad $\mathrm{TiC} / \mathrm{FeAl}$ coating were examined by Nephot-II optical microscope (OM) and KYKY-2800 scanning electron microscope (SEM) with EDX attachment. The phase constitution of laser clad composite coating was identified by Rigaku D/max 2200 type X-ray diffractometer (XRD), using $\mathrm{CuK}_{\alpha}$ radiation operated at a voltage of 40 $\mathrm{kV}$, a current of $40 \mathrm{~mA}$, and scanning rate of $5 \% \mathrm{~min}$.

\section{Results and discussion}

As shown in Fig. 1, the typical microstructure of the middle part in the laser clad $\mathrm{TiC}$ reinforced $\mathrm{FeAl}$ intermetallic matrix composite coating with two different laser scanning speed illustrates that these composite coatings are all composed of primary MC carbide and $\mathrm{MC}$ carbide/FeAl eutectic. Meanwhile, combined with the XRD and EDX analysis results [7], it is clearly shown that the MC carbide reinforced FeAl intermetallic composite coating is successfully fabricated using laser cladding technique.

Fig. 2 shows the rapidly solidified eutectic MC carbide growth morphologies at three laser scanning speed. Clearly, the growth morphologies of eutectic MC carbide are all totally different from both the blocky or Chinese-script conventionally solidified ones and the primary ones reported previously $[9,10]$. Furthermore, the growth morphologies of eutectic MC carbide vary considerably as a function of laser scanning speed. As shown in Fig. 2a, the eutectic MC carbide morphology in the laser clad coating with a laser scanning speed of $5 \mathrm{~mm} / \mathrm{s}$ is needle-aligned annulations. As the laser scanning speed increases to $8 \mathrm{~mm} / \mathrm{s}$, the growth morphology of eutectic MC carbide is indicated in Fig. 2b, and is butterfly-like with a characteristic of regular branching. As the laser scanning speed increases further, the growth morphology of $\mathrm{MC}$ carbide in laser clad coating with a laser scanning speed of 10 $\mathrm{mm} / \mathrm{s}$ is characteristic of well-developed dendrtites. It is worthy noting that the degree of branching increases with increasing laser scanning speed. Also, it is clearly seen the branching angles are nearly same, which implies eutectic MC carbide grows with a crystallographic branching mechanism.

From the above-observed microstructure of laser clad composite coating, MC carbide/FeAl eutectic growth is might followed

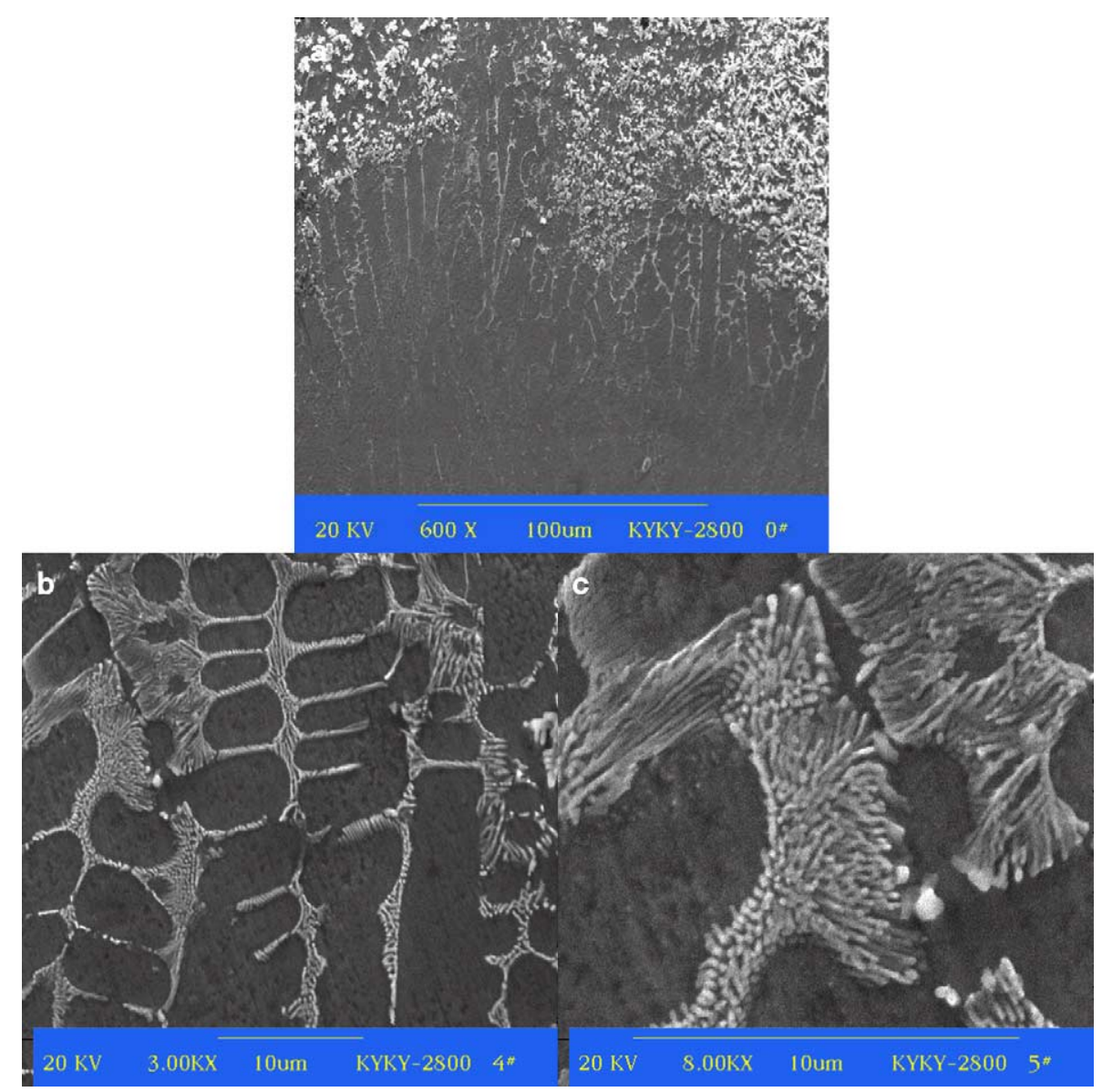

Fig. 3. SEM images showing microstructure of bottom of laser clad TiC/FeAl composite coating (a) and the flower-cluster-like MC carbide (b), (c). 
by the precipitation of primary $\mathrm{MC}$ carbide in the process of the solidification of laser-generated melt pool. It is well known that the eutectic growth is a diffusion-controlled process, and therefore the eutectic MC carbide growth morphology is strongly affected by the cooling rate. Generally, the cooling rate increases with increasing laser scanning speed in the process of laser material processing if other conditions are given. The higher the laser scanning speed, the higher the solidification cooling rate, leading to the smaller the diffusion ability of $\mathrm{MC}$ carbide forming elements in the process of $\mathrm{MC}$ carbide/FeAl eutectic growth. As a result, eutectic $\mathrm{MC}$ carbide can only coordinate the diffusion of MC carbide forming elements by more frequent bifurcating, leading to the degree of branching increases with the increasing of laser scanning speed. Additionally, MC carbide is regards as a typical faceted crystal due to its strong atomic bonding and higher entropy of melting [15], and it therefore grows laterally through these crystal defects such as screw dislocation and/or twins [16]. It is well understood that the density of crystal defects increases drastically with increasing cooling rate [17]. Therefore, the number of the ledges or steps, originated from crystal defects increases with increasing laser scanning speed, and eutectic $\mathrm{MC}$ carbide may bifurcating easily depending upon these much more ledges or steps, resulting in increase in the degree of branching. The intrinsic lateral growth mechanism and the diffusioncontrolled eutectic growth process are the essential factors giving rise to the diversification of eutectic MC carbide morphologies.

It is interesting that no primary $\mathrm{MC}$ carbide is found at the bottom of the laser clad coatings (Fig. 3a), and the growth morphology of these eutectic MC carbide surrounding the FeAl intermetallic alloy takes up to be a flower-cluster-like, as shown in Fig. $3 \mathrm{~b}$ and $\mathrm{c}$, illustrating that the $\mathrm{MC}$ carbide/FeAl eutectic is divorced one. A thin substrate, $1 \mathrm{Cr} 18 \mathrm{Ni}$ TTi stainless steel, is melted with $\mathrm{Fe}-\mathrm{Al}-\mathrm{Ti}-\mathrm{C}$ starting precursor materials placed on its surface during laser cladding, the composition of the laser generated melt pool is inhomogeneous due to alloy elements in melt pool cannot diffuse sufficiently. Therefore, composition of alloy elements at the bottom of melt pool might lie in the scope of the $\mathrm{MC}$ carbide/FeAl eutectic reaction, avoiding the precipitation of the primary MC carbide. Due to the stronger self-cooling effect originated from substrate, the higher cooling rate at he bottom of melt pool can be obtained, leading to the increase in the degree of branching of MC carbide.

\section{Conclusions}

Eutectic MC carbide growth morphology and its evolution with laser scanning speed were studied comprehensively of a laser clad MC carbide reinforced FeAl intermetallic matrix composite coating. As the laser scanning speed increased, the growth morphology of eutectic MC carbide was found to be needle-aligned annulation, butterfly-like and well-developed dendrite. Meanwhile, the eutectic MC carbide at the bottom of the laser clad coating was characteristic of flower-cluster-like due to the strongest self-cooling effect from substrate. The intrinsic lateral growth mechanism and the diffusion-controlled eutectic growth process are the essential factors giving rise to the diversification of eutectic MC carbide morphologies.

\section{Acknowledgement}

The research was supported by the National Natural Science Foundation of China (No. 59971003).

\section{References}

[1] N.S. Stoloff, Mater. Sci. Eng., A Struct. Mater: Prop. Microstruct. Process. 258 (1998) 1

[2] C.G. Mckamey, J.H. Devan, P.F. Tortorelli, V.K. Sikka, J. Mater. Res. 61 (1991) 1779.

[3] J.H. Schneibel, C.A. Carmichae, in: R.G. Cornwall, G.L. Messing, R.G. German (Eds.), Marcel Dekker, New York, p. 253.

[4] J.H. Schneibel, C.A. Carmichael, E.D. Specht, R. Subramanian, Intermetallics 5 (1997) 61.

[5] S.H. Ko, S. Hanada, Intermetallics 7 (1999) 947.

[6] R. Subramanian, J.H. Schneibel, Mater. Sci. Eng., A Struct. Mater: Prop. Microstruct. Process. 239 (1997) 633.

[7] Y. Chen, H.M. Wang, Surf. Coat. Technol. 168 (2003) 30

[8] Y. Chen, H.M. Wang, Surf. Coat. Technol. 179 (2004) 252.

[9] R. Fernandez, J.C. Lecomte, T.Z. Kattamis, Metall. Trans., A, Phys. Metall. Mater. Sci. 9 (1978) 1381.

[10] L. Liu, H.Z. Fu, Z.X. Shi, Acta Aeronaut. Astronaut. Sinica 7 (1986) 181.

[11] L. Liu, F. Sommer, H.Z. Fu, Scr. Metall. Mater. 30 (1994) 584.

[12] H.M. Wang, J.H. Zhang, Y.J. Tang, Z.Q. Hu, N. Yukawa, M. Morinaga, Y. Murata, Mater. Sci. Eng., A Struct. Mater.: Prop. Microstruct. Process. 156 (1992) 109.

[13] Y. Chen, H.M. Wang, J. Alloys Compd. 351 (2003) 304.

[14] Y. Chen, H.M. Wang, Scr. Mater. 50 (2004) 507.

[15] H.Z. Fu, L. Liu, X.H. Fang, J. North. Polytech. Univer. 5 (1987) 279, (in Chinese)

[16] M.C. Flemings, Solidification Processing, McGraw_Hill, New York, 1974.

[17] K.A. Jackson, Liquid Metals and Solidification, ASM, Cleveland. OH, p. 181. 